\title{
Determination of Antibiotic Resistance Pattern in Staphylococcus Aureus Isolated From Patients Referred to Hospitals and Medical Centers of Tabriz City, Iran
}

\author{
*Corresponding Author \\ Davod Tarbiat-nazloo

\section{Article History} \\ Received: 31.12 .2019 \\ Accepted: 07.01.2020 \\ Published: 13.01.2020
}

Fariba Rahmani, Ali Rasooli, Arash Khani, Davod Tarbiat-nazloo"

Tehran University of Medical Sciences, Iran

\begin{abstract}
Background and purpose: Staphylococcus aureus is a common pathogen of nosocomial infections. Increased infections caused by this bacterium in developing countries have led to many problems. The aim of this study was to determine the prevalence of antibiotic resistance of $S$. aureus isolated from urinary tract infections to some commonly used antibiotics. Materials and Methods: In this cross-sectional descriptive study, 100 S. aureus isolates were collected from patients with urinary tract infections. These isolates were identified using standard laboratory and culture methods in a specific medium. Kirby-Bauer disk diffusion method was used to evaluate the antibiotic susceptibility pattern of the strains. Results: Phenotypic evaluation of antibiotic resistance pattern of $S$. aureus strains showed the highest resistance to antibiotics methicillin and penicillin (91\%), erythromycin $(86 \%)$ and gentamicin $(75 \%)$ and the highest sensitivity was related to The antibiotics were nitrofurantoin (95\%) and vancomycin (86\%). Conclusions: The present study showed increased resistance to different antibiotics by $S$. aureus, which is a serious warning for treatment of $S$. aureus infections in the area. Therefore, in order to prevent increased resistance to other antibiotics, it is necessary to refrain from unnecessary administration of available antibiotics.
\end{abstract}

Keywords: Staphylococcus aureus, Urinary Tract Infection, Antibiotic Resistance.

\section{INTRODUCTION}

Staphylococcus aureus, Gram-positive and coagulase-positive from the Staphylococcus family and an opportunistic infectious agent in humans [1-4]. Staphylococcus aureus is a multivalent pathogen and one of the causative agents of disease in hospitals and community level $[5,6]$. It can range from relatively mild infections to life-threatening systemic infections. Due to the genome structure of this bacterium, pathogenic and resistant strains are expanding [7-9]. These infections include soft tissue infections, skin infections, scabies, endocarditis, osteomyelitis and food poisoning[10, 11]. At present, the development of methicillin-resistant strain of Staphylococcus aureus has become one of the major therapeutic challenges. This strain is one of the leading causes of skin and tissue infections in the United States and is primarily responsible for post-surgical infections that produce toxins and sometimes shock[12]. The continued emergence of multidrug-resistant bacteria in many health care institutions has challenged the efficacy of clinical antibiotics, most of which are beta-lactam antibiotics such as penicillin, methicillin, oxacillin and cephalosporins[13, 14]. Recent studies have estimated that 12 to $8 \%$ of hospitalized patients suffer from the side effects of infection. Identification and treatment of colonized individuals can reduce the incidence of MRSA[15-17].Given the importance of awareness of the pattern of susceptibility and resistance of common infectious agents in hospitals to their antibiotic treatment and lack of investigation in Tabriz hospitals, the aim of this study was to evaluate the antibiotic resistance pattern in S. aureus isolated from hospitalized patients and health centers in Tabriz.

\section{MATERiALS AND MeTHODS}

This descriptive cross-sectional study was performed on $100 \mathrm{~S}$. aureus isolates. The isolates were isolated from urinary tract infection using standard laboratory methods. Kirby Bauer disk diffusion method was used to evaluate drug

Copyright @ 2020: This is an open-access article distributed under the terms of the Creative Commons Attribution license which permits unrestricted use, distribution, and reproduction in any medium for non commercial use (NonCommercial, or CC-BY-NC) provided the original author and source are credited. 
sensitivity. Bacteria grown on Blood Agar medium $\left(37^{\circ} \mathrm{C}\right.$ for one day) were used to prepare a suspension of equivalent half-McFarland tube. Antibiogram testing for antibiotic discs (antibody therapy) including discs with standard concentrations of vancomycin $(30 \mu \mathrm{g})$, cefexime $(30 \mu \mathrm{g})$, ciprofloxacin $(5 \mu \mathrm{g})$, nitrofurantoin $(30 \mu \mathrm{g})$, azithromycin $(15$ $\mu \mathrm{g})$, clindamycin $(2 \mu \mathrm{g})$, Ceftriaxone $(30 \mu \mathrm{g})$, imipenem $(10 \mu \mathrm{g})$, penicillin $(10 \mu \mathrm{g})$, methicillin $(5 \mu \mathrm{g})$, erythromycin $(15$ $\mu \mathrm{g})$, gentamicin $(10 \mu \mathrm{g})$ and tetracycline $(10 \mu \mathrm{g})$ were performed.

\section{RESULTS}

Of $100 \mathrm{~S}$. aureus isolates, $59 \%$ belonged to women and $41 \%$ to men. The mean age of the subjects was $41.15 \pm$ 21.15. Based on the antibiotic resistance pattern of the samples, the highest antibiotic resistance was observed to methicillin and penicillin (91\%), erythromycin (86\%) and gentamicin (75\%). Nitrofurantoin (95\%) and vancomycin $(86 \%)$ had the highest sensitivity. All of the clinical isolates had multiple antibiotic resistances. The pattern of antibiotic resistance in S. aureus isolates isolated from clinical samples of Tabriz is presented in Table 1.

Table-1: Frequency of antibiotic resistance pattern of $S$. aureus strains isolated from urinary tract infections

\begin{tabular}{|l|c|c|c|}
\hline antibiotic & sensitive & intermediate & Resistant \\
\hline Vancomycin & 86 & 3 & 11 \\
\hline Cefexime & 48 & 9 & 43 \\
\hline Ciprofloxacin & 58 & 30 & 12 \\
\hline Nitrofurantoin & 95 & 1 & 4 \\
\hline Azithromycin & 18 & 11 & 71 \\
\hline Clindamycin & 5 & 40 & 55 \\
\hline Ceftriaxone & 18 & 22 & 60 \\
\hline Imipenem & 20 & 11 & 69 \\
\hline Penicillin & 2 & 7 & 91 \\
\hline Methicillin & 2 & 7 & 91 \\
\hline Erythromycin & 4 & 10 & 86 \\
\hline Gentamicin & 12 & 13 & 75 \\
\hline Tetracycline & 14 & 20 & 66 \\
\hline
\end{tabular}

\section{DiscuSsion AND CONCLUSION}

Antibiotic resistance is one of the most important microbial threats in the 5th century and the treatment of staphylococcal infections has always been one of the slippery slopes in the treatment of microbial infections. These organisms are of great importance due to the potential of emerging antibiotic resistance in the management of nosocomial infections [18]. Therefore, the highest antibiotic resistance was observed in methicillin and penicillin (91\%), erythromycin $(86 \%)$ and gentamicin $(75 \%)$. The highest sensitivity was related to nitrofurantoin (95\%) and vancomycin $(86 \%)$ antibiotics. Nourbakhsh and Momtaz showed in a 2015 study that the highest antibiotic resistance to methicillin $(90.2 \%)$, erythromycin $(89.7 \%)$, ciprofloxacin $(89.5 \%)$, penicillin $(88 \%)$, tetracycline $(82.4 \%)$, gentamicin $(75.8 \%)$ and the lowest resistance to antibiotics were nitrophorantoin (2\%) and vancomycin (10\%)[19]. In 2014, Saadat et al. Studied the antibiotic resistance pattern of $S$. aureus, the highest susceptibility of the strain to ciprofloxacin, rifampin, linezolid, and sinerside antibiotics $(91.1 \%)$ and the lowest sensitivity to penicillin antibiotics (4.7\%) reported [20]. Vaez et al. showed the highest resistance of MRSA strains to penicillin in 104 strains (100\%), co-amoxiclav 102 strains (97.6\%), cefotaxime 74 strains (71.4\%) and erythromycin 67 strains, respectively (64.3\%), respectivel[21]. Tabaei et al. by analyzing the antibiotic resistance pattern of the isolates, showed that the highest resistance to penicillin antibiotics was $68.3 \%$, erythromycin $52.5 \%$, clindamycin $42.6 \%$ and gentamicin 24\%, respectivel [22]. Similar to Haghgu et al.'s 2012 study in Tabriz, resistance to aminoglycoside and ciprofloxacin antibiotics was low [23], and the highest resistance to penicillin was observed, similar to other studies in the country [24]. The difference of resistance in this study compared to other studies can be related to the difference of resistance in different areas or even in one area hospitals, differences in routine laboratory methods and quality of discs produced by different types of domestic and foreign company's Different studies. There have been reports of rapid spread of resistant strains in hospitals. The present study also highlights the risk of these infections in hospital systems. Because of the high clinical significance of these infections, the need for physicians' knowledge and planning to improve the methods of identifying and controlling such infections is a top priority in medical systems.

\section{REFERENCES}

1. Sales, A. J., Shadbad, N. N., \& Kaleybar, V. P. (2015). The Investigation of the Antibacterial effects of Ethanol extract of Cichorium intybus L. on Antibiotic-resistant Staphylococcus aureus strains. Bull Env Pharmacol Life Sci, 4, 161-4. 
2. Hariss, L., Foster, S., Richards, R. (2002). An introduction to staphylococcus aureus, and techniques for identifying and quantifying s. aureus adhesins in relation to adhesion to biomaterials: Review. Eur Cells Mater, 4:39-60.

3. Jafari-Sales, A., Jafari, B., Sayyahi, J., \& Zohoori-Bonab, T. (2015). Evaluation of antibacterial activity of ethanolic extract of malva neglecta and althaea officinalis 1 . On antibiotic-resistant strains of staphylococcus aureus. $J$ Biol Today World, 4(2), 58-62.

4. Jafari-sales, A., \& Shadi-Dizaji, A. (2019). Evaluation of Inhibitory Effect of Methanol Extract of Allium Sativum in vitro on Staphylococcus aureus and Escherichia coli. Scientific Journal of Nursing, Midwifery and Paramedical Faculty, 5(1), 61-68.

5. Hamdan-Partida, A., Sainz-Espuñes, T., \& Bustos-Martínez, J. (2010). Characterization and persistence of Staphylococcus aureus strains isolated from the anterior nares and throats of healthy carriers in a Mexican community. Journal of clinical microbiology, 48(5), 1701-1705.

6. Jafari-Sales, A., Shahniani, A., Fathi, R., Malekzadeh, P., Mobaiyen, H., \& Bonab, F. R. (2017). Evaluation of Antibacterial Activity of Essential Oil of Ziziphora clinopodioides and Achillea wilhelmsii on Antibiotic-resistant Strains of Staphylococcus aureus. Internal Medicine and Medical Investigation Journal, 2(2), 49-56.

7. Shittu, A. O., Okon, K., Adesida, S., Oyedara, O., Witte, W., Strommenger, B., ... \& Nübel, U. (2011). Antibiotic resistance and molecular epidemiology of Staphylococcus aureus in Nigeria. BMC microbiology, 11(1), 92.

8. Sales, A. J. (2014). Evaluation of antibacterial activity of ethanol extract of Lavandula Stoechas L. plant on antibiotic-resistant strains Of Staphylococcus Aureus. Journal of Current Research in Science, 2(6), 641.

9. Qasmi, M. N., Usmanghani, K., Hannan, A., Nazar, H., Uddin, S., Mohiuddin, E., \& Akram, M. (2012). Clinical evaluation of herbal medicine for essential hypertension. Journal of Medicinal Plants Research, 6(25), 4189-4192.

10. Lowy, F. D. (2003). Antimicrobial resistance: the example of Staphylococcus aureus. The Journal of clinical investigation, 111(9), 1265-1273.

11. Sales, A. J., \& Mobayyen, H. (2014). Detection of the Antibiotic Resistance Pattern in Staphylococcus Aureus Isolated from Urinary Tract Infections in Marand City. Iranian Journal of Public Health, 43(2), 86.

12. Jafari-Sales, A., Farhadi, F., Ezdiyadi, M., \& Tarbiat-Nazloo, D. (2018). Study of antibiotic resistance pattern in methicillin-resistant Staphylococcus aureus isolated from clinical samples of hospitals in Tabriz-Iran. International Journal of Biomedicine and Public Health, 1(2), 71-75.

13. Dibah, S., Arzanlou, M., Jannati, E., \& Shapouri, R. (2014). Prevalence and antimicrobial resistance pattern of methicillin resistant Staphylococcus aureus (MRSA) strains isolated from clinical specimens in Ardabil, Iran. Iranian journal of microbiology, 6(3), 163.

14. Jafari-Sales, A., \& Jafari, B. (2019). Evaluation of the Prevalence of mec A Gene in Staphylococcus aureus Strains Isolated from Clinical Specimens of Hospitals and Treatment Centers. Pajouhan Scientific Journal, 17(3), 41-47.

15. Köck, R., Becker, K., Cookson, B., van Gemert-Pijnen, J. E., Harbarth, S., Kluytmans, J. A. J. W., \& Tacconelli, E. (2010). Methicillin-resistant Staphylococcus aureus (MRSA): burden of disease and control challenges in Europe.

16. Imeni, N., Ghiami Rad, M., Farah Bakhsh, H., \& Jafari-Sales, A. (2019). The Frequency of Methicillin and Vancomycin Resistance Genes in Staphylococcus aureus Strains Isolated from Clinical Specimens in Marand, Iran. Infection Epidemiology and Microbiology, 5(2), 9-16.

17. Sales, A. J., Malekzadeh, P., Ebrahimzadeh, M., Kondlaji, K. B., Kaleybar, V. P., \& Dizaji, A. S. (2015). Evaluation of the anti-bacterial effects of ethanolic extract of yarrow (Achillea wilhelmsii) on antibiotic-resistant strains of Staphylococcus aureus. Journal home page: http://www. journalsci. com ISSN, 2322, 326X.

18. Shittu, A. O., \& Lin, J. (2006). Antimicrobial susceptibility patterns and characterization of clinical isolates of Staphylococcus aureus in KwaZulu-Natal province, South Africa. BMC Infectious diseases, 6(1), 125.

19. Nourbakhsh, F., \& Momtaz, H. (2015). Detection of antibiotic resistance patterns in Staphylococcus aureus strains isolated from patients admitted to Isfahan hospitals during 2014-2015. KAUMS Journal (FEYZ), 19(4), 356-363.

20. Saadat, S., Solhjoo, K., Kazemi, A., \& Mradaneh, J. (2014). Antibiotic resistance pattern of Staphylococcus aureus strains isolated from personnel of Jahrom Hospitals in 2012. Armaghane danesh, 18(10), 826-835.

21. Vaez, H., GHAZI, S. K., MORADI, A., TABARAEI, A., Khodabakhshi, B., Bazouri, M., \& GHAEMI, E. E. (2010). Antibiotic resistance pattern of methicillin resistant Staphylococcus aureus isolated from Health-educational centers of Gorgan, Iran, 2008-2009.

22. Tabaei, S., Kouhi Noghondar, M., Mohammadzadeh, M., Ataei, L., \& Amel Jamehdar, S. (2016). Pattern of antibiotic resistance in methicillin-resistant Staphylococcus aureus (MRSA) strains isolated from clinical specimens: Imam Reza hospital in Mashhad. Medical journal of mashhad university of medical sciences, 59(2), 64-70.

23. Haghgu, S., Moadeb, S., \& Rafi, A. (2012). Determination antibiotic resistance pattern of Staphylococcus strains isolated from Blood Cultures in Shahid Madani Hospital (Tabriz). Jondishapoor Journal, 3(2), 384-90.

24. BehzadianNeghad, G., Anvari, M. (1995). Antibiotic resistance patterns and plasmid profiles of 200 clinically isolated Staphylococcus aureus. Journal of Semnan University of Medical Sciences, 2: 67-72. 